\title{
Determinants of Academic Status in Higher Education
}

\author{
Tadele Bayu: Department of Economics, Debre Tabor University, Ethiopia
}

\begin{abstract}
The main objective of this paper is to figure out the main factors that determine academic status in a higher education institution. Based on the data collected from 218 students using structured questionnaire the researcher uses graphical, tabular and maximum likelihood estimations techniques address the stated objective. Both the graphical illustrations and the maximum likelihood results of ordered logit and ordered probit estimates indicate that gender, age, previous academic background (i.e., students grade twelve university entrance result as a proxy), department choice have a significant effect on the academic status of student at a higher institution. The findings show that female students have a higher probability of being academically poor than male given all other factors the same. Forcing students to join a department without their choice has adverse negative effect on students' academic status. The other variables which directly affect students academic status is students' previous academic background. Based on the findings the researcher recommends that Student's academic background and their first department choice should be seriously emphasized by the ministry of education when students are assigned for each university and faculty at national level.
\end{abstract}

Key words: Academic Performance, Ordered Logit, Ordered Probit, Brant Test.

\section{Introduction}

Since the beginning of modern education the determinants of students' academic performance has been one of the thematic areas for scientific researchers. Though measuring academic performance is challenging (Tahir \& Raza, 2006) the most widely used indicator of students' performance is their academic achievement in the form of their semester grade point average (SGPA) or cumulative grade point average (CGPA). This achievement depends on different individual, family and environmental backgrounds' of students. Gender and age of the student, department choice, access to reference and internet, and family financial support are among the candidate variables. Other factors like the quality of the teaching faculty at a student's school and the presence of harmonious teacher and student relationship may also have a significant effect on students' performance. Wang, Haertel, and Welberg's (1993) review of empirical literature on the correlates and predictors of academic achievement, indicated that student characteristics exhibit the most significant direct influence on achievement. Walberg's theory of academic achievement posits those psychological characteristics of individual students and their immediate psychological environments influence educational outcomes of cognitive, behavioral, and attitudinal skills (Reynolds \& Walberg, 1992).

Psychosocial characteristics such as self-concept, attitudes, behaviors, intrinsic motivation, and overall student engagement in learning are useful in academic performance, and can provide teachers with useful information to arrange more optimally functioning class-rooms (Rugutt \& Chemosit, 2005). According to Rugutt and Chemosit (2005) students' ability to work independently in projects and to discuss coursework with their peer plays a greater role for their academic achievement. 
Empirical literatures such as Howe (1998); Oliver and McLaughlin (2001) explored the role of educational technologies in helping students to exploit their generic skills such as self- management, task management and management of information flow.

Bereket (2015) using chi-square test and logistic regression at Wolaita Sodo University studied about the determinants of academic Performance of Students. His result of cross tabulation with Chi-square test show that age, study outside class, amount of money received from family and first choice of department have significant association with academic performance at 5\% level of significance. Further his result of the logistic regression analysis revealed that preparing time table, father's education level, peer influence; combining ideas and good life later on (motivation) have a significant relation with academic performance at $5 \%$ level of significance.

Previous education researchers figured out various factors that determine students academic performance some using qualitative method and others using quantitative method. Though different techniques and approaches had been tried still the subject is open for debate. Factors such as the effect of department choice on students' academic status and the marginal effects of previous academic background were not clearly explored. In this, paper the researcher diagnosed various factors using econometric techniques of analyzing measured and latent variables which have a non linear association with academic status. Regarding the significance of the present study policy makers especially the ministry of education could be benefited a lot. In Ethiopia unlike many other countries only few students with high entrance exam result are assigned to university based on their first choice. Majority of the students join a department or a program without their interest solely not to lose the chance of the scholarship from the government. The findings of the present study clearly indicate that forcing students to join a program which is not their first choice adversely affect their academic status. Moreover; it will contribute to the existing stock of knowledge and expand the horizon of education policy makers understanding to improve students' academic achievement and success in their academic stay.

\section{Research Methodology}

\subsection{Data Type and Data Sources}

The data for this research has been collected from five different departments and 218 male and female students at Debre Tabor University in 2018 using structured questionnaire. Sample respondents were from the department of economics, accounting, tourism and hotel management, statistics and electrical and computer engineering. The sample also incorporates 118 first year, 76 second year, and 24 third year students.

\subsection{Method of Data Analysis}

The researcher used both descriptive analysis and econometric tools to analyze the characteristics of the sample units and to estimate the results. By applying descriptive statistics, one can compare and contrast different categories of the sample units with respect to the desired characteristics. The descriptive analyses were carried out using box plot.

In the econometric section the study used ordered logit and ordered probit maximum likelihood regression approach to cater ample information that determines student academic status in the study area (Debre Tabor University). First, we identified the academic status of students' as poor, faire, average, good and excellent based on their grade point average (GPA). Then, we estimated the probability of being poor, faire, average, good and excellent conditional on the logistic distribution function and the normal distribution function. In ordered logit and ordered probit, an underlying score the academic status of students was estimated as a linear function of the independent variables and a set of cut points. The probability of observing outcome corresponds to the probability that the estimated linear function, plus random error, is within the range of the cut points estimated for the outcome:

$$
\operatorname{Pr}\left(\text { Outcome }_{\mathrm{j}}=\mathrm{y}^{*}\right)=\operatorname{Pr}\left(\mu_{\mathrm{i}-1} € \mathrm{~B}_{1} \mathrm{x}_{1-1}+\cdots+\mathrm{B}_{\mathrm{k}} \mathrm{x}_{\mathrm{kj}}+\mathrm{u}_{\mathrm{j}} \leq \mathrm{k}_{\mathrm{i}}\right)
$$

The dependent variable(y) academic status will have five categories: Poor, fair average, good and excellent depending on their commutative grade point average the observed ordinal variable, takes on values 1 through 5 according to the following classifications: 


$$
\text { Academic status }\left(\mathrm{Y}^{*}\right)=\left\{\begin{array}{l}
1, \text { if } \mathrm{CGPA} \leq 2.0, \\
L, \text { iI } L . \mathrm{U} \leq \mathrm{CGPA} \leq L . \supset \mathrm{U}, \\
3, \text { if } 2.5 \leq \mathrm{CGPA} \leq 3.0, \\
4, \text { if } 3.0 \leq \mathrm{CGPA} \leq 3.5, \\
5, \text { if } 3.5 \leq \mathrm{CGPA} \leq 4.0,
\end{array}\right.
$$

The dependent variable academic status is assumed to be logistically distributed in ordered logit and normally distributed order probit model. In both case we estimated the coefficients $\beta 1, \beta 1 \ldots \beta \mathrm{k}$ together with the cut points $\mu 1, \mu 2, \mu 3$ and $\mu 4$ where $\mathrm{k}$ is the number of possible outcome.

$\mathrm{Y} *$ is a linear combination of predictor variables as follow

$$
P\left(Y_{i}^{*}=m\right)=\Phi\left(\mu_{m}-X_{i} B\right)-\Phi\left(\mu_{m-1}-X_{i} B\right)
$$

To estimate this model we used MLE, and so first we need a log-likelihood function. This is done by defining an indicator variable $\mathrm{Z}$ which equals 1 if $\mathrm{Y} *=\mathrm{j}$ otherwise. The log-likelihood is simply.

$$
\begin{aligned}
& \text { II L } \underbrace{N}_{2} \underline{m}_{i=1} \ln \left|\Phi_{i i}-\Phi_{i, j}-1^{\prime}\right| \\
& \text { Where } \Phi_{i j}=\Phi\left(\mu_{j}-X_{i} \beta\right) \text { and } \Phi_{i, j-1}=\Phi\left(\mu_{-1}-X_{j} B\right)
\end{aligned}
$$

For ordered logit model, the logistic distribution function is give by

$$
F(z)=\Phi(z)=\frac{e^{z}}{1+e^{z}}
$$

For ordered probit model, $\Phi$ is given by the standard normal cumulative distribution function. The marginal effect of an increase in the independent variable $X_{k}$ on the probability of selecting alternative $j$ is

$$
\frac{\partial P_{i j}}{\partial X_{i j}}=\left[\Phi^{\prime}\left(\mu_{j-1}-X_{j}{ }^{\prime} B\right)-\Phi^{\prime}\left(\mu_{j}-X_{i}{ }^{\prime} B\right){ }_{B}{ }_{k}\right.
$$

Sex: In most rural Ethiopia female students do not have equal chance for school as such initially we had hypothesized the presence of gender disparity in academic status at higher education.

Age: As age goes by attention of the student might be diverted towards other social needs and also remembering what they learn might be very difficult.

G12: It represents university entrance exam result which is considered as a proxy for previous academic background.

DC: As we have stated it in the introductory section all students do not get their first choice department or program in Ethiopia. Only few high achievers in grade 12 university entrance exam result have the opportunity to join their choice departments. Majority of the students join a program without their choice solely not to miss the scholarship from the government. Based on empirical literatures we had hypnotized that department choice has a positive effect on students' academic status.

\subsection{Descriptive Analysis using Box Plot}

Describing dependent and independent variables using graphical illustrations will clearly depict the characteristics of covariates included in the model. 


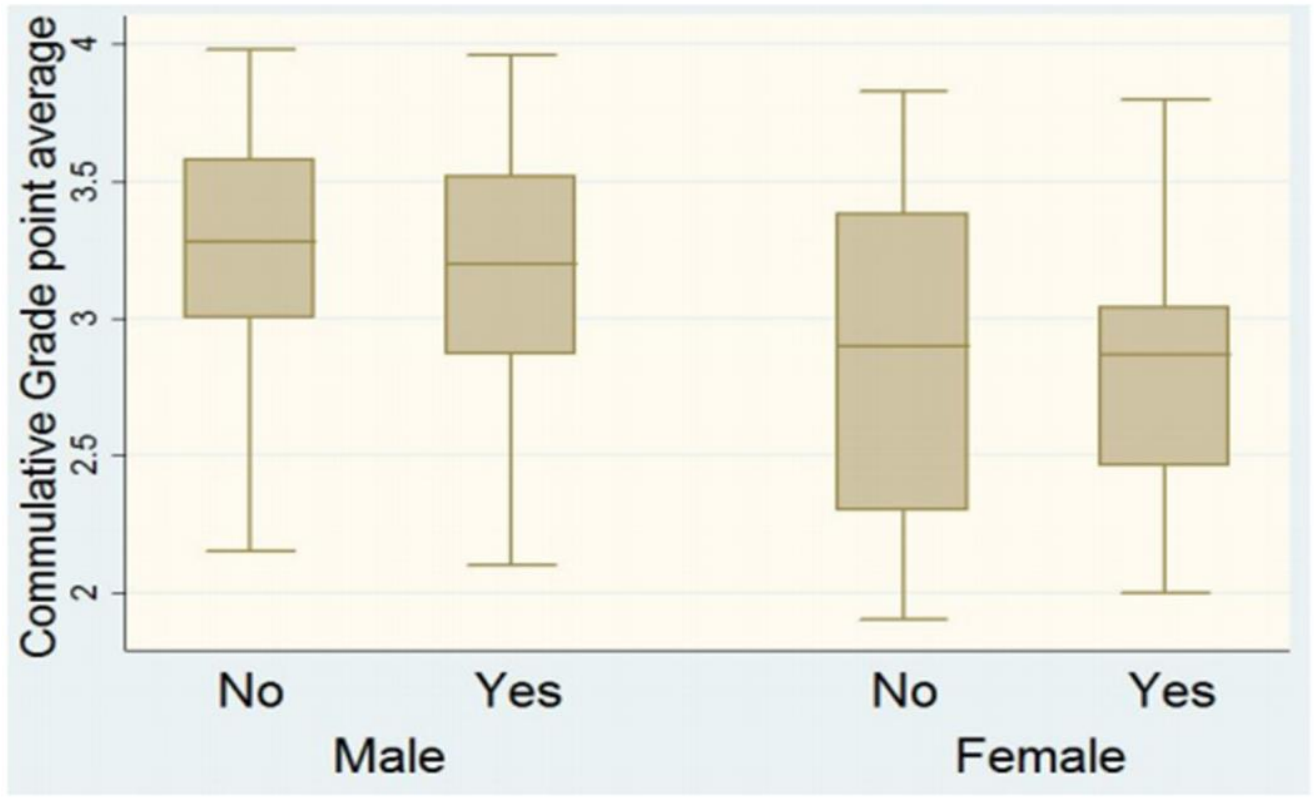

Figure-1.Do you study in your 1 to 5 group?

Using Figure 1 as a reference the median grade for male students who study in a one to five network and those who study independently is identical. However; in the figure it seems there is a slight difference between the median CGPA of female students who study independently and in group. From the collected data female students account about 24 percent and the remaining are male students. Regarding female students status in group study participation about 71 percent do not participate in the established group study network by the university. Only 15 percent of female students are in an excellent academic status. The majority of female students' (i.e., more than 61 percent) are below excellent academic status.

This result is in line with Slavin et al. (1995) argument cited William and Gloriae in 2003 which states that methods which emphasize team building and group process but do not provide specific group rewards based on the learning of all group members are no more effective than traditional instruction in increasing achievement. In Ethiopia almost all universities apply one to five networks for group study. However; its practicality is not that much encouraging. The premise behind group work has been through mutual feedback and debate, peers motivate one another to abandon misconceptions and search for better solutions for a certain problem. But in reality the group leader is the soul responsible body for all assignments and other students are just spectators. Hence; there is no experience from peer communication that can help a student to master social processes, such as participation and argumentation, and cognitive processes, such as verification and criticism its contribution for academic success is negligible.

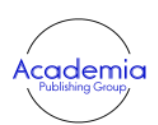

International Journal of Educational Studies Vol. 1, No. 4, pp. 274-283 2018

DOI: $10.53935 / 2641-533 x . v 1 i 4.96$

Funding: This study received no specific financial support.

Article History:

Received: 3 September 2018

Revised: 1 November 2018

Accepted: 5 December 2018

Published: 28 December 2018

(1) 2018 by the authors: licensee Academic

Publishing Group
Table-1. Academic Status and participation in group study.

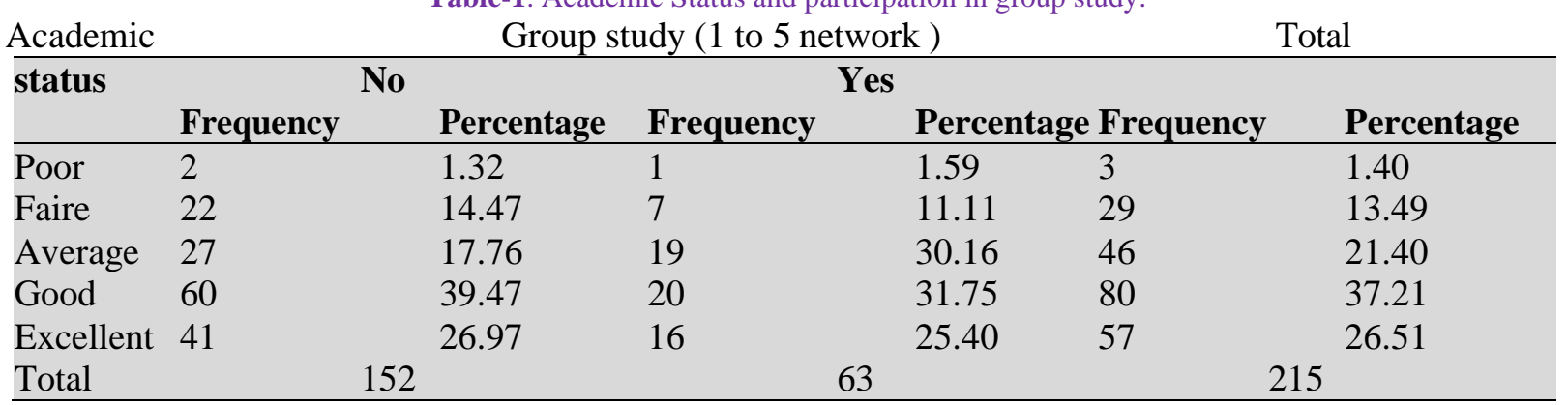

Table 1 presents the distribution of academic status and students' group study participation proportion to the total sample size. The university believes that all students could equally participate in the designed procedure of group work, (usually known as networks) however; the reality is somehow different. More 
than 73 percent of the students who do not participate in group study activities are below excellent academic status. Majority of the students that is about 37 percent have a good academic status in the sample.

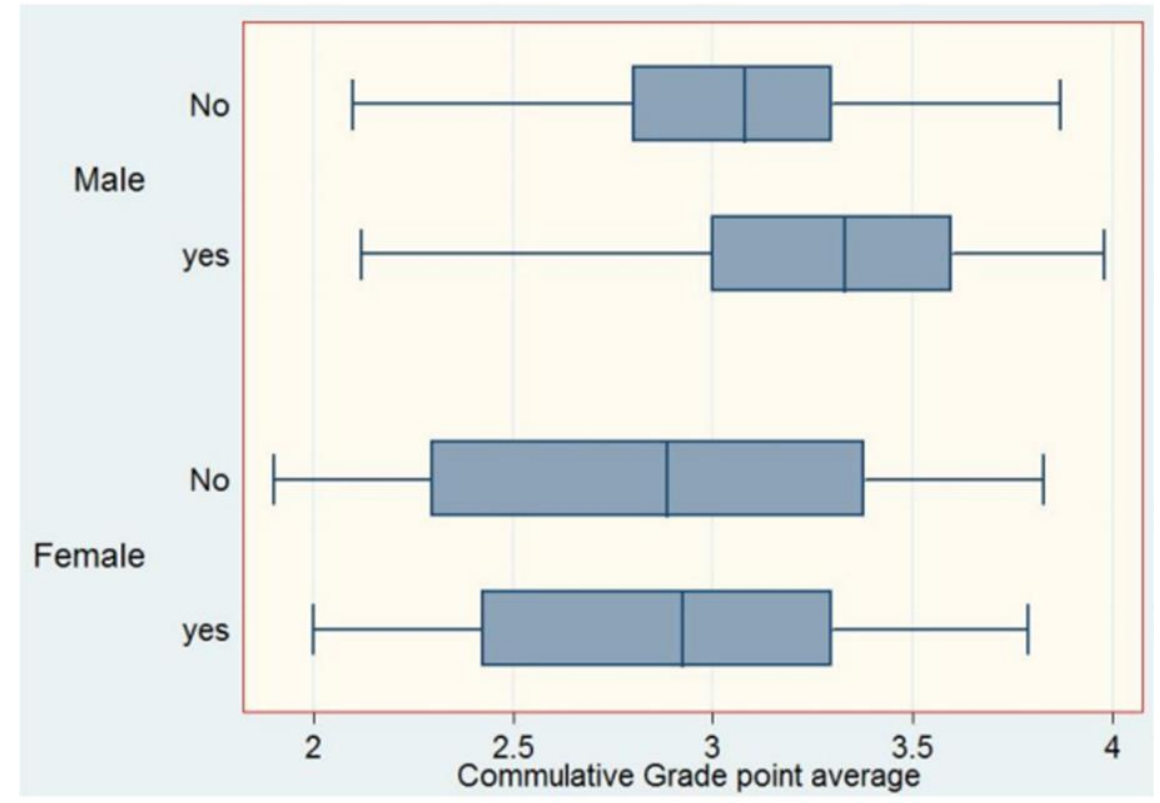

Figure-2. Is your department your firstchoice?.

The box plot in Figure 2 indicates that male students who joined their first choice department score higher grade than those who admitted in the department with compulsory. The difference is highly visible in the case of male students than female students'.

Table 2 shows us the distribution of academic status and group participation to reinforce Figure 2 . About 66 percent of the sample respondents participate in group study. More than 31 percent of the students among those who participate in group study are in excellent academic status. Similarly, among those students who do not participate in group study about 17 percent of the students' are in an excellent academic status.

\begin{tabular}{|c|c|c|c|c|c|c|}
\hline \multirow{3}{*}{$\frac{\text { Academic }}{\text { status }}$} & \multicolumn{4}{|c|}{ Is your department your first choice? } & \multicolumn{2}{|c|}{ Total } \\
\hline & \multicolumn{2}{|c|}{ No } & \multicolumn{2}{|c|}{ Yes } & & \\
\hline & Frequency & Percentage & Frequency & Percentage & Frequency & Percentage \\
\hline Poor & 2 & 2.70 & 1 & 0.69 & 3 & 1.38 \\
\hline Faire & 15 & 20.27 & 15 & 10.42 & 30 & 13.76 \\
\hline Average & 21 & 28.38 & 26 & 18.06 & 47 & 21.56 \\
\hline Good & 23 & 30.08 & 57 & 39.58 & 80 & 36.70 \\
\hline Excellent & 13 & 17.57 & 45 & 31.25 & 58 & 26.61 \\
\hline Total & 74 & & 144 & & 218 & \\
\hline
\end{tabular}

\subsection{Econometric Analysis}

In the next section we provide detail estimation and diagnostic test results of linear probability model, ordered logit model, Barnt's parallel regression assumption test, ordered probit results and marginal effects of gender and department choice. The Brant test indicates that none of the variables violate our parallel regression assumptions and the estimated results supply consistent sign for each variable across models. 


\begin{tabular}{lll}
\multicolumn{3}{c}{ Table-3. Linear probability model. } \\
\hline Variables & COEF & SE \\
\hline SEX & $-0.406^{* *}$ & 0.164 \\
AGE & 0.077 & 0.048 \\
G12 & $0.009 * * *$ & 0.002 \\
DC & $0.321 * *$ & 0.140 \\
Constant & -1.602 & 1.301 \\
Observations & 215 & \\
R-squared & 0.213 & \\
F $(4,210) 14.21$ & & \\
Prob $>\mathrm{F} 0.0000$ & & \\
$* p<0.05, * * p<0.01, * * * p<0.001$ & & \\
\hline
\end{tabular}

In Table 3 for comparison we put the linear probability model result. The result indicates that there is a consistency in sign for each explanatory variable irrespective of the type of estimation techniques used (i.e. linear probability, ordered logit or ordered probit). In the linear probability model sex, previous academic background and department choice are statistically significant at 5 percent, 1 percent and 5 percent respectively. But the linear probability model suffers from heteroskedasticity and non-normality of the error terms. In addition to these shortcomings, the constant slope for each variable and unbounded probability between zero and 1 forces us to turn our attention towards maximum likelihood techniques (i.e., logit and probit models).

\begin{tabular}{|c|c|c|}
\hline VARIABLES & COEF & SE \\
\hline SEX & $-0.756^{* *}$ & 0.327 \\
\hline AGE & $0.172 *$ & 0.092 \\
\hline G12 & $0.019 * * *$ & 0.004 \\
\hline DC & $0.598 * *$ & 0.282 \\
\hline$\mu 1$ & $6.865 * *$ & 2.682 \\
\hline$\mu 2$ & $9.496 * * *$ & 2.636 \\
\hline$\mu 3$ & $10.935 * * *$ & 2.657 \\
\hline$\mu 4$ & $12.830 * * *$ & 2.702 \\
\hline Observations & \multicolumn{2}{|l|}{215} \\
\hline Note: & \multirow{2}{*}{\multicolumn{2}{|c|}{54.01}} \\
\hline LR $3^{2}(4)$ & & \\
\hline $\begin{array}{l}\text { Prob }>3^{2} \\
* p<0.05, * * p<0 .\end{array}$ & \multicolumn{2}{|l|}{0.0000} \\
\hline
\end{tabular}

The result depicted in Table 4 fits ordered logit model for the ordinal dependent variable academic status on the independent variables sex, age, and university entrance exam result and department choice. The hypothesis that the demographic effects of sex, age and non-demographic factors such as grade 12 university entrance exam result and department choice are simultaneously equal to zero can be rejected at the $1 \%$ level, since $3^{2}(4)=$

54.01 with a Prob $>3^{2}=0.0000$. From Table 4 the small p-value from the LR test, $<0.05$, would lead us to conclude that at least one of the regression coefficients in the model is not equal to zero. Together, all the explanatory variables are statistically significant at 1 percent. The result indicates that sex, age, G12 and DC are statistically significant at 5 percent, 10 percent, 1 percent and 5 percent level of significance respectively.

Based on the estimated ordered logit results we would say that when sex is going from 0 to 1 or in other words from male to female, we expect a 0.756 decrease in the log odds of being in a higher level of academic status, given all of the other variables in the model held constant. For a one unit increase in grade twelve university entrance examination results, we would expect a 0.0194 increase in the log odds of being in a higher level of academic status, given that all of the other variables in the model held constant. Though gender concerns are identified and tried to be addressed at every academic level, the result is an indicator of

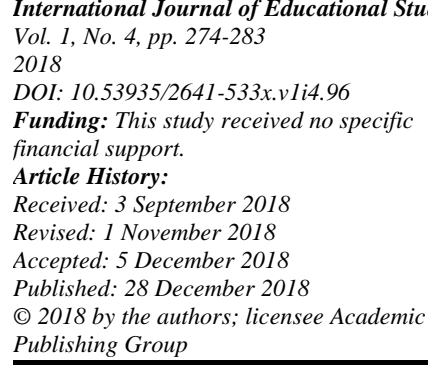


that a lot remains to be done in as far as affirmative action for women is concerned. Achieving the maximum number of female students in a university might not be difficult, but enabling them to cop up with their environment and score like male students requires intervention. That intervention should not be only limited at formulating rules and regulations or setting up a gender office at a certain institution, rather it should be focused on formulating areas and designing projects through which female students can be helped at a higher institution.

\begin{tabular}{|c|c|c|c|}
\hline $3^{2}$ & \multicolumn{2}{|c|}{ Prob $>3^{2}$} & Degree of freedom \\
\hline All & 11.54 & 0.483 & 12 \\
\hline SEX & 0.57 & 0.903 & 3 \\
\hline AGE & 2.08 & 0.555 & 3 \\
\hline G12 & 7.59 & 0.055 & 3 \\
\hline DC & 0.92 & 0.821 & 3 \\
\hline
\end{tabular}

A significant test statistic provides evidence that the parallel regression assumption has been violated. As we can see none of our variables are statistically significantly different from zero at 5 percent. This means that our variables do not violate the parallel regression assumption.

\begin{tabular}{lcl}
\multicolumn{3}{c}{ Table-6. Ordered probit model. } \\
\hline VARIABLES & COEF & SE \\
\hline SEX & $-0.420^{* *}$ & 0.188 \\
AGE & 0.091 & 0.056 \\
G12 & $0.011^{* * *}$ & 0.002 \\
DC & $0.371 * *$ & 0.161 \\
$\mu 1$ & $3.931 * *$ & 1.556 \\
$\mu 2$ & $5.155^{* * *}$ & 1.544 \\
$\mu 3$ & $5.978^{* * *}$ & 1.553 \\
$\mu 4$ & $7.101^{* * *}$ & 1.570 \\
Observations & 215 & \\
\hline Note: $* * * \mathrm{p}<0.01, * * \mathrm{p}<0.05,{ }^{*} \mathrm{p}<0.1$ &
\end{tabular}

The coefficients indicated in Table 6 shows us the estimated ordered probit result. The threshold or intercept parameters $\left(\boldsymbol{\mu}_{1} \boldsymbol{\mu}_{2}, \boldsymbol{\mu}_{3}\right.$, and $\left.\boldsymbol{\mu}_{4}\right)$ are significantly different from each other both in Table 4 and Table 6 so the five categories should not be combined into one. The values indicated in Table 6 clearly reinforce the previous ordered logit values indicated in Table 4 . The signs are consistent with the linear probability model and the ordered logit model.

Table-7. The marginal effect of department choice.

\begin{tabular}{|c|c|c|}
\hline Poor & -0.008 & -0.013 \\
\hline Faire & -0.058 & -0.060 \\
\hline Average & -0.050 & -0.048 \\
\hline Good & 0.0177 & 0.016 \\
\hline Excellent & 0.099 & 0.106 \\
\hline
\end{tabular}

The results stated in the first column of Table 7 indicates the students who joined the department with their first choice will be 0.8 percent , 5.8 percent and 5 percent less likely to be academically poor than students who joined a department with compulsory according to the ordered logit marginal effect result. On the other hand, students who joined the department without compulsory are 1.77 percent and 9.9 percent more likely to be academically good and excellent respectively. 
Similarly, findings stated in the second column of Table 7 shows us the marginal effect of department choice on academic status. Based on the result students who joined a department with their first choice will be

$1.3 \%, 6 \%$ and $4.8 \%$ less likely to be academically poor than students who joined a department with compulsory. On the other hand, students who joined the department without compulsory are $1.6 \%$ and $10.6 \%$ more likely to be academically good and excellent respectively. Students with positive belief for a certain discipline will have a positive effect on their success and efficacy. This is because students will choose their subject based on their cognitive skill and the emotional attachment they do have for that subject.

Table-8. The marginal effect of gender.

\begin{tabular}{lll}
\multicolumn{2}{l}{ Academic Status Ordered Logit Model Ordered Probit Model } \\
\hline Poor & $\mathbf{0 . 0 1 0}$ & $\mathbf{0 . 0 1 5}$ \\
& 0.073 & \\
\hline Faire & 0.063 & 0.068 \\
Average & -0.021 & 0.055 \\
Good & -0.125 & -0.018 \\
Excellent & -0.120 \\
\hline
\end{tabular}

As it is stated in Table 8 the marginal effects show us that, on average, female students are 1 percent more likely than male students that their academic status will be poor, 7.3 per cent and 6.3 percent more likely that their academic status will be fair and average respectively than male students. Moreover, female students are 2.5 and 12.5 percent less likely to be in a good and excellent academic status than male students.



Figure-3. Predicted probabilities of academic status given G12 and gender.

The values indicated in Figure 3 and Table 9 are the predicted probabilities of academic status for different levels of grade 12 university entrance exam result. As it is clearly depicted in the figure the blue line repre-sents the predicted probability of being in an excellent academic status continuously rise with each additional value of grade 12 university exam result. Other cate-gories of academic status i.e. poor, average and good continuously diminish as students grade 12 university entrance exam result increases. The implication of this finding is that those who joined the university with a good academic background in preparatory school will continuoue to score high GPA at the university. 
Table-9. Predicted probabilities of academic status given gender and G12 result

\begin{tabular}{llllll}
\hline & Poor & Fair & Average & Good & Excellent \\
\hline Male G12 Result 360 & 0.0183 & 0.1823 & 0.3010 & 0.3618 & 0.1366 \\
Female G12 Result 360 & 0.0381 & 0.3047 & 0.3329 & 0.2544 & 0.0698 \\
Male G12 Result 400 & 0.0085 & 0.0966 & 0.2179 & 0.4247 & 0.2523 \\
Female G12 Result 400 & 0.0180 & 0.1796 & 0.2993 & 0.3643 & 0.1389 \\
Male G12Result 420 & 0.0058 & 0.0684 & 0.1728 & 0.4236 & 0.3295 \\
Female G12 Result 420 & 0.0123 & 0.1320 & 0.2605 & 0.4044 & 0.1908 \\
Male G12 Result 460 & 0.0027 & 0.0331 & 0.0976 & 0.3575 & 0.5091 \\
Female G12 Result 460 & 0.0057 & 0.0672 & 0.1705 & 0.4229 & 0.3337 \\
Male G12 Result 500 & 0.0012 & 0.0156 & 0.0500 & 0.2468 & 0.6863 \\
Female G12 Result 500 & 0.0026 & 0.0325 & 0.0960 & 0.3550 & 0.5138 \\
Male G12 Result 520 & 0.0008 & 0.0107 & 0.0350 & 0.1925 & 0.7610 \\
Female G12 Result 520 & 0.0018 & 0.0224 & 0.0693 & 0.3011 & 0.6054 \\
Male G12 Result 560 & 0.0004 & 0.0050 & 0.0167 & 0.1064 & 0.8715 \\
Female G12 Result 560 & 0.0008 & 0.0105 & 0.0344 & 0.1899 & 0.7644 \\
Male G12 Result 600 & 0.0002 & 0.0023 & 0.0078 & 0.0539 & 0.9358 \\
Female G12 Result 600 & 0.0004 & 0.0049 & 0.0164 & 0.1047 & 0.8737 \\
Male G12 Result 620 & 0.0001 & 0.0016 & 0.0053 & 0.0376 & 0.9554 \\
Female G12 Result 620 & 0.0003 & 0.0033 & 0.0113 & 0.0750 & 0.9102 \\
Male G12 Result 660 & 0.0001 & 0.0007 & 0.0025 & 0.0179 & 0.9789 \\
Female G12 Result 660 & 0.0001 & 0.0015 & 0.0052 & 0.0369 & 0.9562 \\
Male G12 Result 700 & 0.0000 & 0.0003 & 0.0011 & 0.0084 & 0.9901 \\
Female G12 Result 700 & 0.0001 & 0.0007 & 0.0024 & 0.0176 & 0.9793 \\
\hline
\end{tabular}

\section{Conclusions}

Both the graphical illustrations and the maximum likelihood results of ordered logit and probit results indicate that gender, age, previous academic background (i.e., students grade 12 university entrance result as a proxy), department choice have a significant effect on the academic status of students' at a higher institution. The findings show that female and male are not equal in their academic status based on the data collected and analyzed. Female students have a higher probability to be academically poor than male given all other factors remain constant. One of the most interesting finding of the present study is the effect of academic choice on students' academic status. Forcing students to join a department without their choice will negatively affect students' academic status. The other variables which directly affect the probability of academic achievement in our model is previous academic background using grade twelve university entrance exam result as a proxy variable. As this variable increase the predicted probability of being in an excellent academic status will increase.

\section{Recommendations}

Based on the above findings of the current result gender support via tutorial should be given great emphasis for female students. In addition to providing tutorial, a special guidance and counseling should be strongly organized and involved in the institution. It would be better for female students to have a specific room for reading with in a library with internet facility. Regarding department choice, even though it is totally impossible to assign every student his or her first department choice in a developing country like Ethiopia due to limited resources, great emphasis should be given to give priority for students' interest as much as possible. This is because students' choices makes students active participants in their education, thereby increasing levels of engagement and increase their academic performance. Moreover, students' academic background should be seriously emphasized in the beginning when students are assigned for each faculty and university. 


\section{References}

Bereket, T. (2015). Determinants of academic performance of students: Case of wolaita Sodo University. European Journal of Research and Reflection in Educational Sciences.

Howe, C. (1998). Psychology teaching in the 21st Century: The Psychologist.

Oliver, R., \& McLaughlin, C. (2001). Exploring the practice and development of generic skills through webbased learning. Journal of Educational Multimedia and Hypermedia, 10(3), 207-225.

Reynolds, A. J., \& Walberg, H. J. (1992). A structural model of science achievement and attitude: An extension to high school. Journal of Educational Psychology, 84(3), 371-382.

Rugutt, J. K., \& Chemosit, A. C. (2005). A study of factors that influence college academic achievement: A structural equation modeling approach. Journal of Educational Research \& Policy Studies, 5(1), 6690.

Slavin, S., Naparstek, E., Nagler, A., Ackerstein, A., Kapelushnik, J., \& Or, R. (1995). Allogeneic cell therapy for relapsed leukemia after bone marrow transplantation with donor peripheral blood lymphocytes. Experimental Hematology, 23(14), 1553-1562.

Tahir, H., \& Raza, N. (2006). Factors affecting students' performance: A case of private colleges. Bangladesh e-Journal of Sociology, 3(1), 2. 